\title{
WIRELESS CHEMICAL SENSORS FOR HIGH TEMPERATURE ENVIRONMENTS
}

\author{
Edward Birdsell and Mark G. Allen \\ School of Mechanical Engineering, Georgia Institute of Technology, Atlanta, GA USA \\ School of Electrical and Computer Engineering, Georgia Institute of Technology, Atlanta, GA USA
}

\begin{abstract}
This work reports wireless ceramic chemical sensors operating in high temperature environments. The sensors utilize a passive wireless resonant telemetry scheme to eliminate the need for onboard power and exposed interconnects. An inductorcapacitor (LC) resonator circuit forms the basis for the wireless platform. The sensor inductor is fabricated from electroplated nickel and the capacitor portion of the circuit is fabricated using mixed-oxide ceramic dielectrics. These dielectrics are found to exhibit variations in electrical properties with exposure to differing concentrations of $\mathrm{CO}_{2}$ and $\mathrm{NO}_{\mathrm{x}}$. Dual sensing schemes are presented that utilize the two observed electrical responses in these materials; conductivity changes for $\mathrm{CO}_{2}$ detection and permittivity changes for $\mathrm{NO}_{\mathrm{x}}$ detection. $\mathrm{CO}_{2}$ sensors have been fabricated that are able to function up to $675^{\circ} \mathrm{C}$. $\mathrm{NO}_{\mathrm{x}}$ sensors capable of operating at up to $600^{\circ} \mathrm{C}$, while detecting $\mathrm{NO}$ concentrations below $5 \mathrm{ppm}$, are also presented.
\end{abstract}

\section{INTRODUCTION}

Developing sensors for operation in high temperature environments, such as those found in internal combustion and turbine engines, presents a number of materials related challenges. Previous work, utilizing multilayer ceramic laminated technology from the ceramic packaging industry, has successfully demonstrated devices fabricated from low-temperature co-fireable ceramic (LTCC). In particular, a wireless pressure sensor operating at temperatures up to $450^{\circ} \mathrm{C}[\mathbf{1 , 2}]$ was demonstrated. Temperature limitations of these LTCC devices are due to the glass frit component of the material. While the frit allows for a lower curing temperature, it also introduces a material with a more rapidly increasing conductivity than the pure ceramic. Later work has replaced the LTCC with high purity $\mathrm{Al}_{2} \mathrm{O}_{3}$ to eliminate the frit component and extend the temperature range of the devices. Wireless sensing platforms have been developed that have demonstrated wireless temperature measurement above $1000^{\circ} \mathrm{C}$ [3]. In this work, the high purity alumina sensing platform has been adapted to quantitatively measure chemical concentrations of $\mathrm{CO}_{2}$ and $\mathrm{NO}$.

Typically, a potentiometric approach using solid electrolytes is used for high temperature chemical sensing. However, this approach is difficult to adapt to a passive sensing scheme. Work by Ishihara [4-6] has shown that certain mixed-oxide compositions demonstrate electrical response to various gases at high temperature. In particular, a number of $\mathrm{BaTiO}_{3}$ based mixedoxides exhibit electrical response to $\mathrm{CO}_{2}$ exposure and $\mathrm{ZnO}$ based mixed-oxides to NO exposure. Two specific dielectric compositions have been identified that exhibit electrical responses that are readily employed in a passive sensing approach. An equalmolar mixture of $\mathrm{BaTiO}_{3}-\mathrm{La}_{2} \mathrm{O}_{3}$ has been found to vary in conductivity with exposure to $\mathrm{CO}_{2}$. Similarly, a mixture (1:1 mole ratio) of $\mathrm{ZnO}-\mathrm{WO}_{3}$ has been found to vary in permittivity with exposure to NO. By incorporating these chemically sensitive dielectrics into the capacitor structure of the LC circuit, a chemical sensor can be constructed.

\section{CHEMICAL SENSOR DESIGN}

The equivalent electrical circuit model of the chemical sensor, with a coupled measurement antenna, is illustrated in Figure 1. $L_{a}, L_{s}$, and $L_{m}$ refer to the antenna inductance, sensor coil inductance, and the mutual inductance, respectively. $R_{s}$ is the series resistance of the inductive sensor coil and $R_{p}$ is the parallel resistance, due to leakage, across the sensor capacitor, $C_{s}$. The input impedance, $Z_{a}$, of the antenna can be modeled from this circuit using Equations 1, 2, 3, and 4 (derivation of these equations can be found in prior publications [1]). The results from these equations show that both $C_{s}$ and $R_{p}$ influence the measured antenna impedance, $Z_{a}$. This allows two approaches to sensor design; sensors based on changing material conductivity, and sensors based on changing material permittivity.

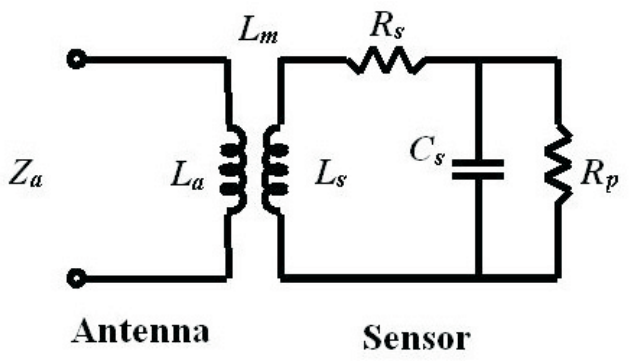

Figure 1. Equivalent circuit of wireless sensor and measurement antenna.

$$
\begin{gathered}
\mathrm{Z}_{a}=\left[\frac{\omega^{2} k^{2} L_{s} L_{a} A}{A^{2}+B^{2}}+j\left(\omega L_{a}-\frac{\omega^{2} k^{2} L_{s} L_{s} B}{A^{2}+B^{2}}\right)\right] \\
A=R_{s}+\frac{R_{p}}{1+\omega^{2} C_{s}^{2} R_{p}^{2}} \\
B=\omega L_{s}-\frac{\omega C_{s} R_{p}^{2}}{1+\omega^{2} C_{s}^{2} R_{p}^{2}} \quad k^{2}=\frac{L_{m}^{2}}{L_{a} L_{s}}
\end{gathered}
$$

Previous high temperature wireless pressure and temperature sensors have used a parallel plate configuration for the capacitor structure. In these chemical sensors it is necessary to maximize the exposed surface area of the dielectric material. The approach taken here is to replace the parallel plate electrodes with an interdigitated electrode structure. After the electrodes are deposited, the 
chemically sensitive dielectric is added. This significantly simplifies fabrication and enables the deposition of the dielectric as a final step. Figure 2 shows details of the sensor layout.

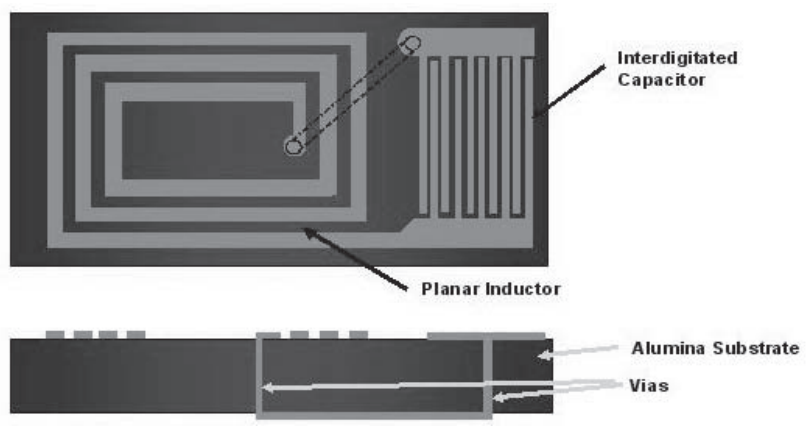

Figure 2. Diagram of wireless sensing platform.

The concern in this case, with a capacitor structure utilizing interdigitated electrodes, is that the underlying and unresponsive dielectric of the sensor body will contribute significantly to the overall capacitance of the LC circuit, thereby lowering the sensitivity. However, due in part to the high dielectric constant of the chemically-sensitive material, modeling shows that the induced electrical energy is concentrated in the chemically sensitive dielectric layer (Figure 3). As a result, changes in this layer dominate the response of the sensor.

a)

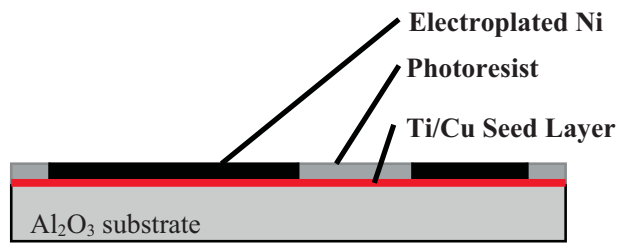

b)

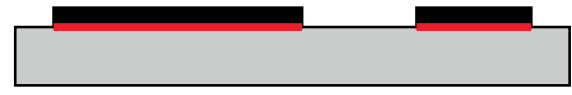

c)

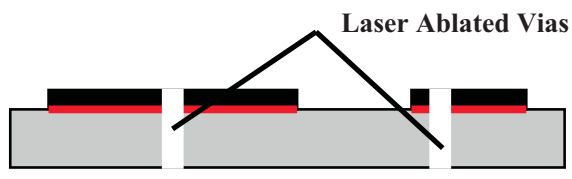

d)

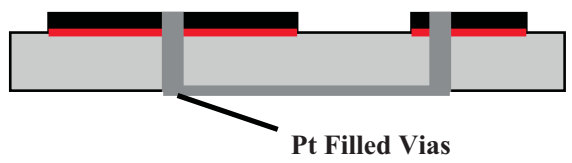

Chemically Sensitive

Dielectric

e)

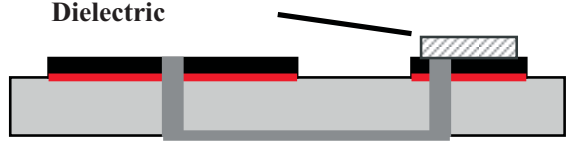

Figure 4. Process flow for sensor fabrication.

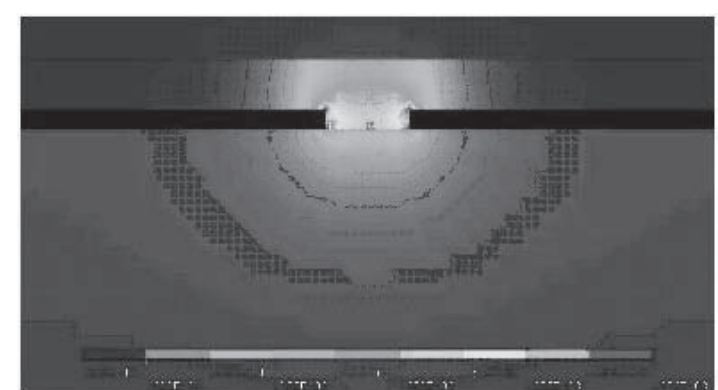

Figure 3. Modeling results indicate electric field lines are localized in chemically- sensitive material.

\section{CHEMICAL SENSOR FABRICATION}

The fabrication process for the chemical sensors is divided into two parts. First, the wireless sensing platform is formed by electroplating the inductor and capacitor electrode structure. Second, the chemically responsive mixed-oxide dielectric is prepared and deposited using stencil printing.

\section{A. Ni electroplated inductive coil and interdigitated capacitor electrode structures}

A metal seed layer consisting of $30 \mathrm{~nm}$ of Ti and $400 \mathrm{~nm} \mathrm{Cu}$ is DC sputtered on $50.8 \mathrm{~mm} \times 50.8 \mathrm{~mm} \times 0.66 \mathrm{~mm}$ high-purity alumina (99.6\%) thin-film substrates obtained from Coors Ceramics Company (Superstrate 996). These substrates have a non-polished (as-fired) surface finish. Next, a 30 micron layer of thick photoresist (Futurrex NR9-8000) is deposited. This layer is photo-lithographically patterned to form molds for electroplating the inductor and capacitor electrode structures. 10 microns of $\mathrm{Ni}$ is next electroplated using a nickel sulfamate bath at a current density of $5 \mathrm{~mA} \cdot \mathrm{cm}^{-2}$. The deposition rate was measured to be $0.32 \mathrm{um} \cdot \mathrm{min}^{-1}$ (Figure 4a). After electroplating, the photoresist and seed layer are removed (Figure 4b). Two interconnect vias are drilled through the alumina substrate using a Nd:YLF laser (Figure 4c). A platinum ink (Dupont 9141) electrical trace is screen printed on the back side of the substrate to complete the LC circuit (Figure $4 \mathrm{~d})$. The ink is dried at $100^{\circ} \mathrm{C}$ for one hour to drive off solvents. Afterwards the ink is heated to $1000^{\circ} \mathrm{C}$ in an air atmosphere at a ramp rate of $10^{\circ} \mathrm{C} \cdot \mathrm{min}^{-1}$ and held for 30 minutes to cure before cooling to room temperature at a rate of $10^{\circ} \mathrm{C} \cdot \mathrm{min}^{-1}$.

\section{B. Mixed-oxide dielectric material}

The preparation of the chemically sensitive dielectric material is identical for both mixed oxide compositions $\left(\mathrm{BaTiO}_{3}-\mathrm{La}_{2} \mathrm{O}_{3}\right.$ for $\mathrm{CO}_{2}$ detection and $\mathrm{ZnO}-\mathrm{WO}_{3}$ for $\mathrm{NO}_{\mathrm{x}}$ detection) and uses traditional powder processing techniques. Commercially available powders of high purity, fine grained $\mathrm{BaTiO}_{3}$ and $\mathrm{La}_{2} \mathrm{O}_{3}$ or $\mathrm{ZnO}$ and $\mathrm{WO}_{3}$ are combined to form a 1:1 mole ratio. The powder batch is ball milled with water in a $250 \mathrm{~mL}$ Nalgene bottle for $24-$ 48 hours at $60 \mathrm{rpm}$. Alumina cylinders, $12.7 \mathrm{~mm}$ diameter x 12.7 $\mathrm{mm}$ length, are used as grinding media. This milling process serves to break up any powder conglomerates, mix the components, and reduce the overall grain size of the material. The resulting mixture is highly uniform in particle size and composition. After milling, the liquid slurry is poured into a 20 $\mathrm{mm} \times 150 \mathrm{~mm}$ Pyrex ${ }^{\circledR}$ Petri dish. The slurry is baked at $90^{\circ} \mathrm{C}$ for 6 hours to completely remove the water. Once dry, the powder is used to create a screen-printable ink. The mixed-oxide is combined with glycerin and mixed using a mortar and pestle. A weight ratio 
of glycerin to powder of approximately $0.1: 1$ produces ink with an acceptable consistency and viscosity for screen or stencil printing.

The dielectric ink is then stencil printed, using a $10 \mathrm{~mm} x$ $14 \mathrm{~mm}$ stencil opening, on to the surface of the interdigitated capacitor electrodes (Figure 4e). The entire sensor is then heated at a rate of $3^{\circ} \mathrm{C}^{\circ} \cdot \mathrm{min}^{-1}$ to $700^{\circ} \mathrm{C}$ and held for a duration of five hours before cooling to room temperature at $10^{\circ} \mathrm{C} \cdot \mathrm{min}^{-1}$. This process serves two functions. First, it removes the glycerin used in the ink formation $\left(290^{\circ} \mathrm{C}\right.$ decomposition temperature). Second, the five hour dwell calcines the mixed oxide mixture. An insignificant amount of sintering occurs during the calcining and the resulting mixture remains porous upon cooling to room temperature. Previous x-ray diffraction work with this material indicates that it remains a simple mixture of the beginning mixed-oxide powders after the calcining process. Figure 5 shows an image of a fabricated sensor. The outside dimensions of the sensor are $25 \mathrm{~mm}$ x $40 \mathrm{~mm}$.

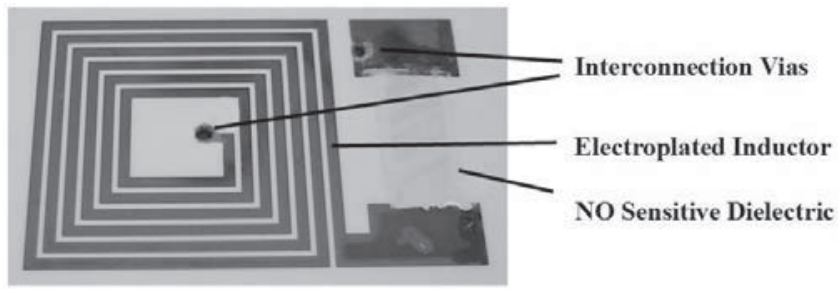

Figure 5. Fabricated sensor with electroplated nickel inductive coil. NO sensitive dielectric stencil printed over capacitor electrodes.

\section{CHEMICAL SENSOR TESTING}

Measurements for the chemical sensors are conducted using a Lindberg box furnace (Model BF51848) that has a maximum temperature of $1100^{\circ} \mathrm{C}$. The furnace is fitted with a feed-through to pass a loop antenna inside the heated chamber. The antenna is constructed from a $50 \mathrm{~cm}$ length of $1 \mathrm{~mm}$ diameter NickelChromium wire sheathed in a protective alumina multi-bore tube (AluSik-99 ZA or equivalent). The sensor is placed within the plane of the antenna loop and the impedance, $Z$, of the antenna is measured as a function of frequency using an HP4194A impedance analyzer. The furnace is ramped to each measurement temperature point and allowed to equilibrate for 30 minutes before data is taken. A K-type thermocouple located directly adjacent the sensor serves to monitor localized temperature and confirm accuracy. In order to control the atmosphere within the furnace, a $1 \mathrm{~mm}$ I.D. stainless tube is inserted through the furnace floor. This tube is connected to the output of two MKS Instruments mass flow controllers used to mix the incoming gas. The controllers supply a constant flow of dry air at a rate of $163 \mathrm{smL} \cdot \mathrm{min}^{-1}$. This flow is sufficient to create a positive pressure within the furnace and allow control of atmospheric conditions within the test chamber. Varying concentrations of the test gases are metered into the constant flow to alter the chamber atmosphere.

\section{A. $\mathrm{CO}_{2}$ wireless sensor - variable conductivity dielectric}

The sensor is placed in the test chamber, heated to $675^{\circ} \mathrm{C}$ at $5^{\circ} \mathrm{C} \cdot \mathrm{min}^{-1}$, and allowed to stabilize for 6 hours. Once stabilized, baseline measurements are taken. Various concentrations of $\mathrm{CO}_{2}$ are next fed into the chamber. Each concentration of $\mathrm{CO}_{2}$ is exposed to the sensor for a period of five minutes prior to measurement. Between $\mathrm{CO}_{2}$ exposures, the chamber is purged with dry air for 30 minutes. Figure 6 shows the response of the sensor to varying $\mathrm{CO}_{2}$ concentrations. $\mathrm{BaTiO}_{3}-\mathrm{La}_{2} \mathrm{O}_{3}$ has been shown to have a reduced conductivity when exposed to $\mathrm{CO}_{2}[3]$. As a result, equation 1 predicts a lowering of the impedance phase angle measured at the antenna. This is observed experimentally as shown in Figures 6 and 7. The response is also dependent on concentration enabling the quantitative measurement of $\mathrm{CO}_{2}$.

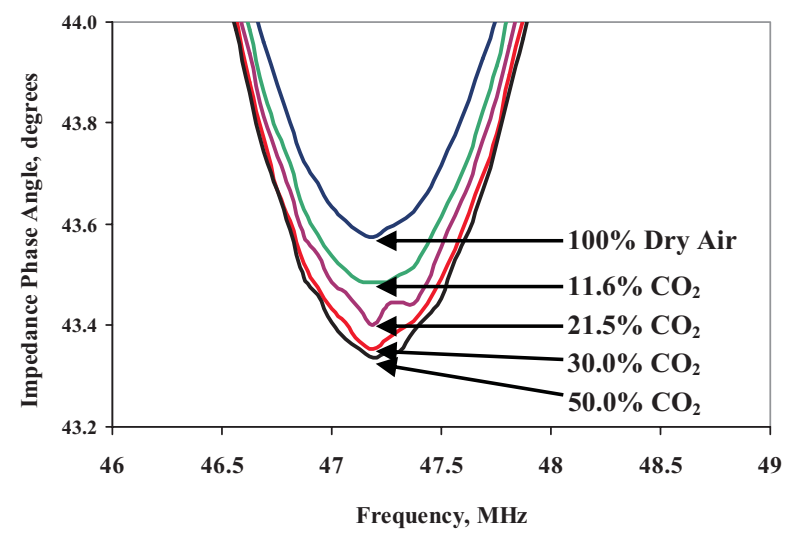

Figure 6. $\mathrm{CO}_{2}$ sensor $\left(\mathrm{BaTiO}_{3}-\mathrm{La}_{2} \mathrm{O}_{3}\right)$ at $675^{\circ} \mathrm{C}$ demonstrates variation in magnitude of impedance phase angle with exposure to $\mathrm{CO}_{2}$.

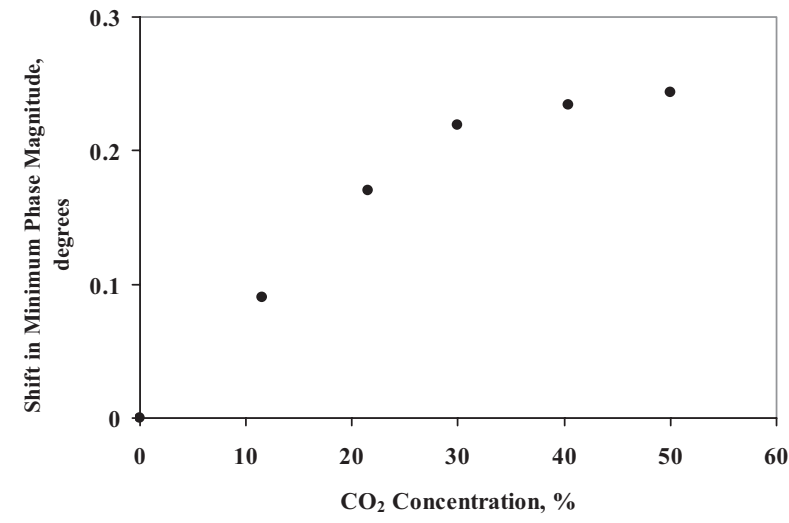

Figure 7. Sensor response dependence on to gas concentration enabling quantitative measurements of $\mathrm{CO}_{2}$.

\section{B. NO wireless sensor - variable permittivity dielectric}

The NO sensor was tested over two concentration ranges (above and below $40 \mathrm{ppm}$ NO). For high NO concentrations the sensor is placed in the test chamber and heated to $400^{\circ} \mathrm{C}$ at $5^{\circ} \mathrm{C} \cdot \mathrm{min}^{-1}$ and allowed to stabilize for 6 hours. Once stabilized, baseline measurements are taken and the sensor is exposed to NO concentrations ranging from $40-1400 \mathrm{ppm}$. The atmosphere is controlled by combining dry air with a $10,000 \mathrm{ppm}$ certified concentration $( \pm 2 \%)$ of $\mathrm{NO}$ in a nitrogen carrier gas. As with the $\mathrm{CO}_{2}$ sensors, the chamber is purged with dry air for 30 minutes between measurements. The sensor is exposed to each concentration of $\mathrm{NO}$ for a period of five minutes prior to measurement. The $\mathrm{ZnO}-\mathrm{WO}_{3}$ mixed oxide dielectric exhibits a change in permittivity as opposed to the change in conductivity 
observed in $\mathrm{BaTiO}_{3}-\mathrm{La}_{2} \mathrm{O}_{3}$. As a result, shifts in the resonant frequency of the sensor are expected. Figure 8 shows the response of the sensor for NO concentrations greater than $40 \mathrm{ppm}$. Above approximately $500 \mathrm{ppm}$, this response plateaus and is thought to be the result of saturation. However, for applications involving the monitoring of exhaust gases, NO concentrations in the tens of ppm and below are of most interest.

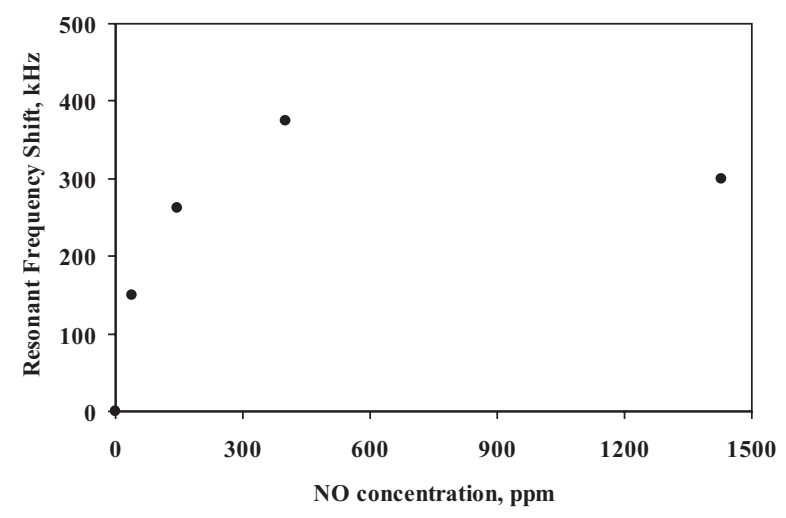

Figure 8. $\mathrm{NO}$ sensor $\left(\mathrm{ZnO}-\mathrm{WO}_{3}\right)$ exhibits saturation effects above 500 ppm at $400^{\circ} \mathrm{C}$.

Testing of the sensor with lower NO concentrations follows a similar procedure as outlined above for the higher concentrations. To obtain accurate atmospheric concentrations below $40 \mathrm{ppm}$ NO, a dry air flow was combined with a certified NO concentration of $1000 \mathrm{ppm}( \pm 2 \%)$ in a nitrogen carrier gas. In these tests the test chamber is heated to $600^{\circ} \mathrm{C}$ in order to explore the temperature limitation of the sensing material. The sample is heated to the target temperature at the same $5^{\circ} \mathrm{C} \cdot \mathrm{min}^{-1}$ and allowed to stabilize for 6 hours. Once stabilized, baseline measurements are taken. Figure 9 shows the response of the sensor to NO concentrations below $40 \mathrm{ppm}$. The sensor exhibits a measurable shift in resonant frequency even below the $5 \mathrm{ppm}$ level where the average response is $30 \mathrm{kHz} \cdot \mathrm{ppm}^{-1}$. Response of the sensor is proportional to NO concentration and demonstrates quantitative passive wireless measurement of $\mathrm{NO}$ below $5 \mathrm{ppm}$ at $600^{\circ} \mathrm{C}$.

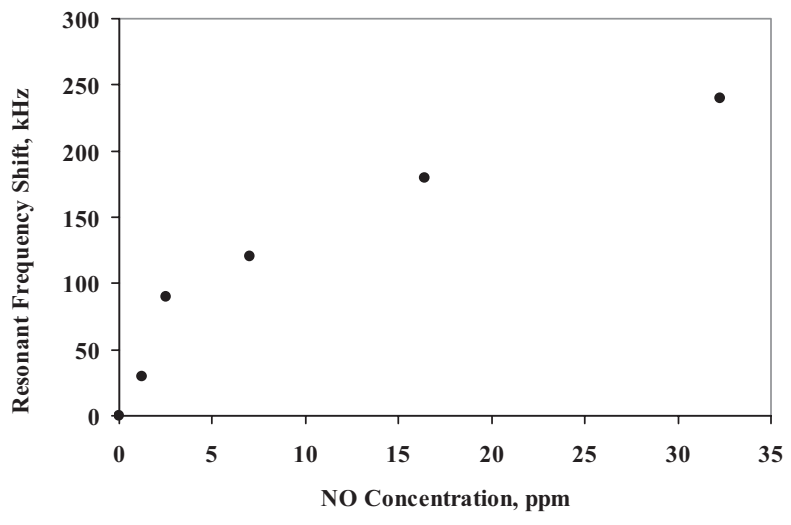

Figure 9. NO sensor exhibits measurable shifts in resonant frequency in response to concentrations below $40 \mathrm{ppm}$ at $600^{\circ} \mathrm{C}$.

$\mathrm{ZnO}-\mathrm{WO}_{3}$ characterization by Ishihara [5] has previously shown permittivity reductions exceeding $50 \%$ for NO exposure in similar ranges. However, this characterization was preformed at a significantly lower frequency $(50 \mathrm{kHz})$ than the typical $40-60$ $\mathrm{MHz}$ operating regime of these sensors. Observed permittivity reduction in $\mathrm{ZnO}-\mathrm{WO}_{3}$, based on resonant frequency shift, is approximately $3 \%$ (at $35 \mathrm{ppm}$ ). It is believed that the notable difference between the previously characterized bulk material and the 'as-fabricated' material is due, at least in part, to this difference in operating frequency.

\section{CONCLUSIONS}

Two passive wireless chemical sensors have been presented. A $\mathrm{CO}_{2}$ sensor based on the conductivity changes in $\mathrm{BaTiO}_{3}-\mathrm{La}_{2} \mathrm{O}_{3}$ has been demonstrated to quantitatively measure $\mathrm{CO}_{2}$ concentrations at $675^{\circ} \mathrm{C}$. An $\mathrm{NO}$ sensor based on permittivity changes in $\mathrm{ZnO}_{-} \mathrm{WO}_{3}$ has successfully measured $\mathrm{NO}$ concentrations below $5 \mathrm{ppm}$ at $600^{\circ} \mathrm{C}$. The wireless sensing platform developed for these sensors can be readily adapted to sense a variety of other gases and even other phenomena by incorporating a dielectric that produces an electrical response to the property of interest.

\section{ACKNOWLEDGEMENTS}

This project was supported in part by NASA and DoD under the URETI program on Aeropropulsion and Power Technology. The authors would like to thank Dr. Jin-Woo Park for valuable technical discussions.

\section{REFERENCES}

[1] M.A. Fonseca, J.M. English, M. von Arx, M.G. Allen, "Wireless Micromachined Ceramic Pressure Sensor for HighTemperature Applications", Journal of Microelectromechanical Systems, Vol. 22, No. 4, Aug. 2002

[2] J.M. English, M.G. Allen, "Wireless Micromachined Ceramic Pressure Sensors", Proceedings IEEE MEMS '99, pp. 511-516, 1999

[3] E.D. Birdsell, J. Park, M.G. Allen, "Wireless Ceramic Sensors Operating in High Temperature Environments", $40^{\text {th }}$ AIAA/ASME/SAE/ASEE Joint Propulsion Conference, Fort Lauderdale, FL, July 2004

[4] T. Ishihara, K. Kometani, M. Hashida, Y. Takita, “Applications of Mixed Oxide Capacitor to the Selective Carbon Dioxide Sensor", Journal Electrochemical Society, Vol. 138, No. 1, Jan. 1991

[5] T. Ishihara, S. Sato, Y. Takita, "Capacitive-Type Sensors for the Selective Detection of Nitrogen Oxides", Sensors and Actuators B, Vol. 24-25, pp. 392-395, 1995

[6] T. Ishihara, S. Sato, Y. Takita, "Sensitive Detection of Nitrogen Oxides Based Upon Capacitance Changes in Binary Oxide Mixture", Sensors and Actuators B, Vol. 30, pp. 43-45, 1996 